\title{
Síndrome do esgotamento profissional Revisão Bibliográfica
}

Resumo: Nas últimas décadas, pesquisadores de várias áreas têm se preocupado com o fenômeno Síndrome do Esgotamento Profissional (SEP) caracterizada como doença do trabalho. Considerada o estágio mais avançado do estresse, a SEP afeta inúmeras profissões, principalmente aquelas em que os profissionais possuem contato direto com pessoas, entre os quais, os professores. A revisão bibliográfica com textos em língua portuguesa, inglesa e espanhola sobre o tema permitiu unificar a expressão do fenômeno como "Síndrome do Esgotamento Profissional" (SEP). O aprofundamento de estudos sobre esse fenômeno em determinados coletivos docentes, como os professores de Educação Física, possibilitará ampliar a compreensão e elaborar significativos questionamentos envolvendo o trabalho docente e o fenômeno descrito na bibliografia. Destaca-se que nessa revisão de literatura, foram encontrados poucos trabalhos envolvendo coletivos de trabalhadores docentes. No caso dos professores de Educação Física, foco de interesse investigativo deste estudo, raros foram os trabalhos encontrados sobre o assunto.

Palavras-chave: "Burnout", Síndrome do Esgotamento Profissional Professores de Educação Física.

Neste estudo examina-se de que modo a Síndrome do Esgotamento Profissional (Burnout) ${ }^{1}$ vem sendo tratada na literatura referente ao tema. Aborda-se esta questão social, através de alguns conceitos e definições utilizadas para descrever o fe-

* Mestrando em ciências do movimento humano- ESEF/UFRGS. Professor da Universidade Luterana do Brasil - Campus Canoas e professor da Rede Estadual de Ensino.

1 Bum (queima) out (para fora) ou simplesmente "Burnout" é uma expressão inglesa criada para designar os processos de esgotamento psicológico vivenciados em relação ao trabalho (MOURA, 1997)

Movimento, Porto Alegre, v. 10, n. 1, p. 183-209, janeiro/abril de 2004 
nômeno, destacando-se algumas das diferenças existentes entre a Síndrome do Esgotamento Profissional e o estresse, e de que modo vários autores utilizam diferentes expressões como sinônimos do fenômeno.

Discorre-se, também, sobre o modo com que o processo da SEP se manifesta em profissionais que mantêm uma relação constante e direta com outras pessoas, incluindo-se, aí, os professores, as reações que a síndrome causa no organismo, seus aspectos agravantes ou minimizadores, seus efeitos e algumas estratégias de prevenção.

O termo "Burnout" na bibliografia consultada tem o significado de "síndrome de quemarse por ei trabajo" em espanhol. Neste estudo opta-se pelo emprego da expressão em língua portuguesa - "Síndrome do Esgotamento Profissional - (Anexo II do decreto 3.048, de 06 de maio de 1999, Secretaria da Previdência Social do Ministério da Previdência Social) com o mesmo significado de "Síndrome de Burnout".

Ao analisar a literatura existente sobre o tema, partindo-se de uma visão geral para a específica, constata-se pouca produção na área de conhecimento da Educação Física e Ciências do Esporte $^{2}$ sobre o tema. Essa revisão se constitui na fundamentação teórica de uma investigação mais ampla que tematiza a relação da Síndrome do Esgotamento Profissional (SEP) e os professores de Educação Física.

$2 \mathrm{Na}$ revisão de literatura sobre a Síndrome do Esgotamento Profissional foram encontrados somente dois artigos em língua estrangeira específica na área da Educação Física que foram apresentados no $\|^{\mathbb{Q}}$ Congresso Mundial de Atividade Física e Esportes de Granada - Espanha - em 2003. São eles: CARRARO, A., TISATO, F, COGNOLATO, S. \& BETOLLO, M. Burn out risk for physichal education teachers Actas del II Congreso Mundial de la Actvidad Física y el Deporte: Deporte y Cualidad de Vida. p.54-59. Granada/ES: Universidad de Granada, 2003 e, GONZALES HERRERO, E., MONFORT PANEGO, M., PASCUAL BANOS, C. La materia de educación física como desencadeante del burn out en el profesorado. Actas del II Congreso Mundia de la Actividad Física y el Deporte: Deporte y Cualidad de Vida. p. 127-131. Granada/ES. Universidad de Granada, 2003.

Movimento, Porto Alegre, v. 10, n. 1, p. 183-209, janeiro/abril de 2004 


\section{Síndrome do Esgotamento Profissional (SEP)}

\section{Um breve histórico}

Historicamente, segundo Carlotto (2001) apenas na década de 1970, no mundo, é que começaram a ser construídos modelos teóricos e instrumentos capazes de registrar e compreender esse sentimento crônico de desânimo, de apatia, de despersonalização. Trata-se de uma síndrome que afeta principalmente os trabalhadores encarregados de cuidar, ou seja, pessoas que trabalham em contato direto com outras - médicos, assistentes sociais, psicólogos, enfermeiros, professores, entre outros. Freudenberger (1974), médico psicanalista, que teve uma vida profissional permeada de frustrações e dificuldades que o levaram à exaustão física e mental foi o primeiro a tratar desse tema. Descreveu a SEP como um sentimento de fracasso e exaustão causado por um excessivo desgaste de energia e recursos, incluindo em sua definição, através de estudos posteriores, comportamentos de fadiga, irritabilidade, depressão, aborrecimento, sobrecarga de trabalho, rigidez e inflexibilidade.

O estudo de Farber (1984) aponta Cristina Maslach, Ayala Pine e Cary Cherniss como sendo os estudiosos que popularizaram o conceito de SEP e o legitimaram como uma importante questão social. Maslach (1976) afirma que a síndrome surge em várias profissões e que mesmo com diferentes nomes é o mesmo fenômeno básico ocorrendo em uma grande variedade de ambientes de trabalho.

Segundo Carlotto (2001), um estudo descritivo realizado por McGuire, em 1979 faz o primeiro registro da síndrome em professores. Para a autora, a partir da década de 1980, novas pesquisas apresentaram resultados onde foram identificados sintomas em grupos profissionais que até então não eram considerados populações de risco. Por tratar-se de profissões vocacionais, os investigadores acreditavam que esses profissionais obtinham gratificações em todos os níveis, pessoais e sociais. Esses estudos mostravam a ocorrência da SEP em pessoas com personalidades ajustadas e equilibradas em ambientes de trabalhos específicos.

Em 1981, realizou-se, na Filadélfia (USA) a $1^{\text {a }}$ Conferência Nacional Americana sobre a SEP a qual serviu para unificar critérios e divulgar os trabalhos realizados sobre pequenas amostras

Movimento, Porto Alegre, v. 10, n. 1, p. 183-209, janeiro/abril de 2004 
ou sobre experiências próprias (Oliveira, 2001). Carlotto e Gobbi (2000) pontuam que os avanços nos estudos da SEP têm evoluído à medida que se qualificam as questões metodológicas desde sua fase pioneira.

Na décima revisão da Classificação Internacional de Doenças (CID-10, 1989), o "Burnout" figura como Síndrome de Esgotamento Profissional dentro de um grupo de classificação que tem como título "problemas relacionados à organização de seu modo de vida".

Hoje, sabe-se que o estresse relacionado ao trabalho está presente e causa muitos males. Neste sentido, o Correio Brasiliense (2002) cita estudos realizados pelo ISMA (International Stress Management Association) em nove países, apontando os trabalhadores brasileiros entre os mais estressados do mundo no quesito Esgotamento Profissional, o estágio mais avançado do estresse.

No Brasil, o Secretário da Previdência Social do Ministério da Previdência e Assistência Social tornou pública a nota explicativa sobre o Anexo II do Decreto 3.048, de 06 de maio de 1999, apresentando as 14 classificações de doenças que podem estar relacionadas ao trabalho, em que se encontra a definição da doença designada como a sensação de estar acabado ("Síndrome do Esgotamento Profissional" ou "Síndrome de Burnout").

\section{Definições}

De acordo com Codo e Vasquez-Menezes (1999), a SEP é uma expressão que designa aquilo que deixou de funcionar por exaustão de energia. É algo como "perder o fogo", "perder a energia", ou, numa tradução mais direta, é quando o trabalhador perde o sentido da sua relação com o trabalho, de forma que as coisas já não o importam mais e qualquer esforço lhe parece inútil.

Já, para Farber (1984), esse fenômeno é o resultado do estresse excessivo, último passo na progressão dos propósitos fracassados de manejar e diminuir uma variedade de situações negativas do trabalho. É uma resposta ao estresse crônico quando outros mecanismos de ajuste não funcionam.

Movimento, Porto Alegre, v. 10, n. 1, p. 183-209, janeiro/abril de 2004 
A este respeito, Seligmann-Silva (1995) nos diz que a SEP designa um conjunto de respostas a situações estressantes próprias do trabalho, cuja especificidade reside na necessidade de interação e cuidado constante com outras pessoas no exercício das atividades profissionais, enquanto que, para Oliver et al. (1996) é um tipo de estresse laborai crônico e cotidiano que aparece com freqüência em profissionais que mantêm uma relação constante e direta com outras pessoas: médicos, enfermeiros, terapeutas, assistentes sociais, psicólogos, professores, etc.

Ainda no tocante a este ponto, Carlotto (2001) entende que a síndrome é um fenômeno psicossocial, um tipo de estresse de caráter persistente vinculado a situações de trabalho resultante da constante e repetitiva pressão emocional associado a intenso envolvimento com pessoas por longos períodos.

Gil-Monte e Peiró (1999) assinalam que não existe uma definição unânime sobre a SEP, porém há um certo consenso de que a mais utilizada e aceita é fundamentada na perspectiva socialpsicológica elaborada por Maslach e Jackson que consideram a SEP uma reação à tensão emocional crônica, caracterizada pelo esgotamento físico e/ou psicológico, por uma atitude fria e despersonalizada em relação às pessoas e um sentimento de inadequação em relação às tarefas a serem realizadas. As características do trabalho são os principais determinantes da tendência do indivíduo em relação à SEP. $\mathrm{O}$ trabalhador se envolve afetivamente com os seus clientes, se desgasta e, num extremo, desiste, não agüenta mais.

A esse respeito, Maslach e Jackson (1981) afirmam que a SEP é constituída por três componentes:

a) Exaustão Emocional - Caracteriza-se por uma falta de energia e um sentimento de esgotamento de recursos. A maior causa de exaustão no trabalho é a sobrecarga e o conflito pessoal nas relações. Como afirmam Codo e Vasquez-Menezes (1999, p.242) "é um desgaste de vínculo afetivo na relação indivíduo-trabalho". A exaustão emocional está ligada à falta de recursos emocionais, ao sentimento de que não se é útil aos outros, e que não se tem nada para lhes oferecer. É um componente que pode ter manifestações, quer físicas, quer psíquicas (SILVA, 2000). O receio e o temor de voltar ao trabalho no dia seguinte é um dos sintomas mais comuns.

Movimento, Porto Alegre, v. 10, n. 1, p. 183-209, janeiro/abril de 2004 
b) Despersonalização - Caracteriza-se por tratar os clientes, colegas e a instituicão como objetos. Conforme Codo e Vasquez-Menezes (1999, p. 242) "A despersonalização ocorre quando o vínculo afetivo é substituído por um racional". É um estado psíquico em que prevalece o cinismo ou a dissimulação afetiva, a crítica exacerbada de tudo e de todos os demais e do meio ambiente". A despersonalização é o desenvolvimento de sentimentos negativos, de atitudes e condutas de cinismo frente às pessoas com quem trabalha. Estas pessoas são vistas pelos profissionais de maneira desumana devido a um endurecimento afetivo (Gil-Monte, 2002). Os sintomas comuns nessa fase são ansiedade, irritabilidade, desmotivação, descomprometimento com os resultados, alienação e conduta voltada a si mesmo.

c) Diminuição da realização pessoal no trabalho: Esta fase é caracterizada como uma forma de se auto-avaliar de forma negativa. As pessoas se sentem infelizes com elas próprias e insatisfeitas com seu desenvolvimento profissional. Experimentam um declínio no sentimento de competência e no êxito no seu trabalho e de sua capacidade de interagir com outras pessoas. Esta diminuição no senso da auto-eficácia tem sido relacionada à depressão e à inabilidade em lidar com o trabalho, podendo ser exacerbada pela falta de suporte social e oportunidades de desenvolvimento profissional. "O baixo envolvimento pessoal no trabalho, que também pode ser entendido como baixa realização pessoal no trabalho ocorre nessa relação afeto-trabalho, sendo na verdade, a perda do investimento afetivo" (Codo e Vasques-Menezes, 1999, p.242). É assim, uma experiência subjetiva, envolvendo atitudes e sentimentos que podem acarretar problemas de ordem prática e emocional ao trabalhador e à organização. A ausência de realização pessoal desencadeia uma diminuição das expectativas pessoais e uma crescente autodepreciação, originando, assim, sentimentos de fracasso e baixa auto-estima (Silva, 2000).

De acordo com o que foi exposto acima, é importante ressaltar que nas observações percebidas por Gatto (2000), a despersonalização é o elemento chave do fenômeno, considerando-se que tanto a falta de realização pessoal quanto à exaustão emocional podem ser encontradas em outras síndromes depressivas. Entende-se que, embora a despersonalização seja um dos componentes da SEP, não deve ser analisada separadamente, como uma variável contínua com nível alto, médio e baixo.

Movimento, Porto Alegre, v. 10, n. 1, p. 183-209, janeiro/abril de 2004 
Desta forma, concorda-se com Codo e Vasquez-Menezes (1999) quando diz que é pela combinação de cada um dos componentes que se obtém o nível da SEP do indivíduo ou categoria profissional.

\section{Diferenciação entre estresse e Síndrome do Esgotamento Profissional}

O termo stress, segundo Oliveira (2001), foi introduzido no âmbito da saúde pelo médico austríaco Hans Seyle, na década de 1930, e logo se converteu numa palavra de uso corrente, tanto pelos profissionais das diferentes áreas da saúde, quanto pela população em geral. Hans definiu o estresse como um estado manifesto por uma síndrome específica, constituída por todas as alterações nãoespecíficas produzidas num sistema biológico. $\mathrm{O}$ estresse se manifesta através da síndrome Geral da Adaptação considerada um conjunto de respostas não-específicas a uma lesão e desenvolve-se em três fases: 1) a fase de alarme, caracterizada por manifestações agudas; 2) a fase da resistência, quando as manifestações agudas desaparecem e, 3) a fase da exaustão, quando há a volta das reações da primeira fase e pode levar ao colapso do organismo. $\mathrm{O}$ autor afirma ainda que o estresse pode ser encontrado em qualquer uma das fases, embora suas manifestações sejam diferentes ao longo do tempo.

Para Gallego e Rios (1991) devido ao fator a SEP estar intimamente relacionado com outros conceitos já existentes é difícil estabelecer diferenças claras entre eles, como acontece com o estresse. São muitas as conexões entre um conceito e o outro. A única diferença (mais aparente do que real) é que a SEP é um estresse crônico experimentado num contexto de trabalho. Embora exista um consenso na literatura internacional de que a SEP seria uma resposta ao estresse laborai crônico, este não deve ser confundido com estresse. $\mathrm{O}$ conceito de estresse, por um lado, não envolve tais atitudes e condutas, é um esgotamento pessoal com interferência na vida do indivíduo, e não necessariamente na sua relação com o trabalho (Codo e Vasquez-Menezes, 1999).

Concordando com o autor supracitado, Ballone (2002) faz uma referência de que para autores que defendem a SEP como sendo diferente de estresse, alegam que esta doença envolve atitudes e condutas negativas com relação aos usuários, organização e trabalho, enquanto o estresse apareceria mais como um

Movimento, Porto Alegre, v. 10, n. 1, p. 183-209, janeiro/abril de 2004 
esgotamento pessoal com interferência na vida do sujeito e não necessariamente na sua relação com o trabalho. Para o autor a SEP é a seqüência mais depressiva do estresse desencadeado pelo trabalho.

Em relação ao estresse laborai, Villalobos (2002) conceitua como o conjunto de fenômenos que ocorrem no organismo do trabalhador com a participação dos agentes estressores lesivos, derivados diretamente do trabalho ou se motivado por este podem afetar a saúde do trabalhador.

De acordo com Erosa (2000), o estresse é um fato habitual para a humanidade. Não se pode evitá-lo, já que qualquer mudança a qual se deva nos adaptar representa uma situação de estresse. Os fatos negativos, prejuízos, enfermidades ou morte de um ente querido são situações estressantes e também o podem ser, assim os fatos positivos: ascender profissionalmente traz consigo o estresse pelo novo status profissional, pelas novas responsabilidades assumidas.

Como questão relevante, Farber (1984) afirma que o estresse tem efeitos positivos e negativos para a vida, enquanto a SEP é sempre negativa. É importante ressaltar que, para Corsi (2002), as diferenças entre estresse e a SEP é que o estresse pode desaparecer após um período adequado de descanso e repouso, enquanto que a SEP não regride com as férias e nem com outras formas de descanso.

\section{Expressões utilizadas em relação à Síndrome do Esgotamento Profissional}

$\mathrm{Na}$ literatura existente sobre o tema constata-se que vários autores utilizam termos e expressões para designar o conceito de SEP Com base em estudos compilados, Benevides-Pereira (2002), dá um panorama de algumas expressões utilizadas por vários autores como sinônimos da SEP nas quais é apresentada no Quadro 1. Ressalta, porém, que, embora não haja uma palavra ou expressão que sintetize adequadamente esse conceito a já tão ampla gama de nomenclaturas existentes apresentam uma conotação parcial podendo levar a equívocos acarretando mais dificuldades do que esclarecimentos.

Movimento, Porto Alegre, v. 10, n. 1, p. 183-209, janeiro/abril de 2004 
Quadro 1. Expressões utiltzadas para definir a Síndrome de Esgotamento Profissional

\begin{tabular}{|c|c|}
\hline $\begin{array}{l}\text { Estresse Laboral: } \\
\text {-Tipo de estresse que se dá } \\
\text { no contexto do trabalho. }\end{array}$ & $\begin{array}{l}\text { Büssing \& Glaser, 2000; } \\
\text { Gonzáles,1995; } \\
\text { Herrero, Rivera \& Martín, } \\
\text { 2001; Schaufelli, } 1999 .\end{array}$ \\
\hline $\begin{array}{l}\text { Estresse Laboral Assistencial: } \\
\text { - Em relação ao Estresse Laboral } \\
\text { acrescentam o caráter de ajuda. }\end{array}$ & $\begin{array}{l}\text { Oliver, Pastor, Aragoneses \& Moreno. } \\
\text { Gimenez, 1990; Seisdedos, } 1997 .\end{array}$ \\
\hline $\begin{array}{l}\text { Estresse Profissional: -Ressaltam a } \\
\text { dimensăo profissional da mesma. }\end{array}$ & $\begin{array}{l}\text { May \& Revich, 1985; } \\
\text { Nunes, 1989. }\end{array}$ \\
\hline $\begin{array}{l}\text { Estresse Ocupacional: } \\
\text { - Salientam que os responsáveis } \\
\text { pelos transtornos náo seriam o } \\
\text { trabalho ou a profissáo, mas sim o } \\
\text { tipo de atividade desempenhada. }\end{array}$ & $\begin{array}{l}\text { Firth, } 1985 ; \\
\text { Shoroder, Martín, Fontanais \& Mateo, } \\
1996 .\end{array}$ \\
\hline $\begin{array}{l}\text { Síndrome de queimar-se pelo trabalho: } \\
\text { - Perde-se a esperança pelo trabalho e } \\
\text { que qualquer esforço destinado a fazer } \\
\text { bem as coisas é pouco menos que o } \\
\text { inútil. }\end{array}$ & $\begin{array}{l}\text { Perez, 1997; } \\
\text { Gil-Monte \& Peiró, } \\
\text { 1997 - 1999; } \\
\text { Seisdedos, 1997; }\end{array}$ \\
\hline $\begin{array}{l}\text { Neurose Profissional ou Neurose de } \\
\text { Excelência: } \\
\text {-Transtornos psiquicos agregados ao } \\
\text { trabalho. }\end{array}$ & Stelia, 2001 \\
\hline Estresse Ocupacional: & $\begin{array}{l}\text { Carlatto, 1999; Seidedos, } 1997 \\
\text { Moura,1997 }\end{array}$ \\
\hline $\begin{array}{l}\text { Síndrome do Esgotamento } \\
\text { Profissional: } \\
\text { - Doença relacionada com o trabalho } \\
\text { designada como a sensação de estar } \\
\text { acabado }\end{array}$ & $\begin{array}{l}\text { Moraes, 1999; } \\
\text { Maslach, Schaufeli \& Leiter, } \\
\text { 2001.Ministério da Previdéncia o } \\
\text { Assistência Social (1999) }\end{array}$ \\
\hline
\end{tabular}

Fonte: Estudos realizados Por Benevides-Percira 2002: p. 22 e 23.

Ainda a esse respeito, para Benevides-Pereira (2002), o termo "Burnout" é mantido por não haver uma palavra em português que sintetize adequadamente o conceito desta síndrome. Dentre os termos em português utilizados por vários autores, estes não parecem acrescentar uma melhora substancial à denominação empregada Apresentam conotação parcial ou que pode levar a equívocos, não encontrando necessidade em acrescentar à já tão ampla gama de nomenclaturas existentes, o que mais tem levado a dificuldades do que a esclarecimentos.

Movimento, Porto Alegre, v. 10, n. 1, p. 183-209, janeiro/abril de 2004 
Por outro lado, atualmente, o conceito que vem sendo desenvolvido é SEP, para designar e descrever um conjunto de respostas às situações estressantes próprias da atuação de um trabalho cuja especificidade reside na necessidade de interação e cuidado com outras pessoas. Aqui, a natureza do trabalho em si mesma, constituise na fonte de tensões que acarretariam, para os sujeitos, uma experiência estressora, impondo-lhes a necessidade de reagir de forma específica e estereotipada (Moura, 1997).

\section{A Síndrome do Esgotamento Profissional em professores}

Nos últimos anos, a SEP tem resultado em um dos temas de maior atenção por parte dos investigadores no estudo das profissões assistenciais e de ajuda, incluído-se aí, os professores. A este respeito, Remor (2002), referindo-se aos professores, define SEP como um estresse crônico produzido pelo contato com a demanda escolar, a qual leva-o a uma extenuação e a um distanciamento emocional com os beneficiários do seu trabalho, a uma perda gradual da preocupação e de todo sentimento emocional em relação às pessoas com as quais trabalha, o que o direciona a um isolamento ou desumanização.

Considerando-se que a síndrome é entendida como um conceito multidimensional que envolve exaustão emocional, despersonalização e falta de envolvimento pessoal no trabalho, pode-se afirmar que o professor, nessa situação, se sente totalmente exaurido emocionalmente, devido ao desgaste diário ao qual é submetido no relacionamento com seus alunos. Por um lado, o professor torna-se incapaz do mínimo de empatia necessária para a transmissão do conhecimento. Por outro, sua auto-estima é baixa, há sentimento de exaustão física e emocional.

Segundo Jiménez, Gutiérez, Hernandez (1994), um professor experimentaria esgotamento emocional ao sentir não poder dar aos seus alunos mais de si mesmo; mostraria despersonalização ao desenvolver atitudes negativas, cínicas e às vezes insensíveis em relação aos estudantes, pais e companheiros, e teria sentimentos de baixa realização pessoal ao ver-se ineficaz na hora de ajudar seus alunos no processo de aprendizagem e de cumprir com outras responsabilidades de seu trabalho. Os autores tam-

Movimento, Porto Alegre, v. 10, n. 1, p. 183-209, janeiro/abril de 2004 
bém apontam como determinantes principais da SEP em professores, uma lista de conflitos, por exemplo: a tentativa de resolver problemas disciplinares dos alunos quando se vê frente à falta de apoio e inclusive a beligerância de pais ou superiores; políticas inconsistentes e confusas a respeito da conduta dos estudantes; a sobrecarga de trabalho (falta de tempo, excessivo trabalho administrativo, etc); problemas disciplinares, apatia dos estudantes e seu baixo rendimento, a escassa participação na tomada de decisões e o apoio social recebido por parte dos companheiros e supervisores.

Somam-se a isso as características do ambiente de trabalho, que podem desencadear esse tipo de sofrimento mental. Violência, falta de segurança, uma administração insensível, pais omissos, críticos da opinião pública, classes superlotadas, falta de autonomia, salários inadequados, falta de perspectivas de ascensão na carreira, isolamento em relação a outros adultos ou falta de uma rede social de apoio, além de preparo inadequado, são fatores que têm se apresentado associados à síndrome. Pode ocorrer também, o sentimento de derrota.

Um ponto interessante e motivo de reflexão é citado por Codo e Vasquez-Menezes (1999), quando apontam que a SEP é uma desistência de quem ainda está lá. Encalacrado em uma situação de trabalho que não pode suportar, mas também que não pode desistir. $O$ trabalhador arma, inconscientemente, uma retirada psicológica, um modo de abandonar o trabalho, apesar de continuar no posto. Está presente na sala de aula, mas passa a considerar, cada aula, cada aluno, cada semestre, como números que vão se somando em uma folha em branco. A síndrome é um fenômeno real que vai avançando com o tempo, corroendo o ânimo do educador e, dia após dia, o fogo vai se apagando devagar.

\section{SEP: Como surge? Como se desenvolve?}

A síndrome é ura processo individual que se desenvolve com o passar do tempo. Não surge de maneira súbita, emergindo de forma paulatina, cumulativa, com progresso em severidade. Sua evolução pode levar anos e até mesmo, décadas (Rudow apud Carlotto, 2001). Embora com o passar do tempo apareçam reações no organismo características da síndrome, França (1987) constata que o indivíduo geralmente se recusa a acreditar que 
esteja acontecendo algo de errado com ele. Seu início é marcado por uma sensação de mal-estar físico ou psicológico e por um prolongado nível de tensão.

Alvarez et al. (1993) destaca, ainda, que não é possível determinar com exatidão sua origem, nem sua seqüência, nem as correlações das diferentes fases implicadas no desenvolvimento da síndrome. Apesar disso, o autor sugere algumas etapas que a modo de orientação, têm sido propostas por outros autores:

a) em um primeiro momento em que as demandas do trabalho excedem os recursos materiais e humanos, provocando uma situação de estresse. Há uma tendência em negá-la. O sujeito não aceita as diferenças que outros observam nele, portanto, a síndrome é notada primeiro pelos companheiros (Ballone, 2002);

b) a segunda fase seria a sobrecarga; o sujeito reage dando uma resposta inadequada a esse desajuste, aparecendo sintomas de ansiedade, fadiga, irritabilidade, manifestações emocionais perante atitudes do trabalho; $\mathrm{e}$,

c) na terceira fase, que corresponde ao enfrentamento defensivo, é que se vai produzir uma mudança de atitudes e condutas com o fim de defender-se ativamente e resistir às tensões experimentadas.

\section{SEP: reações corporais}

$\mathrm{Na}$ literatura existe uma lista muito grande de reações provocadas no organismo associadas à síndrome. Autores como Freudenberg, 1974; França, 1987; Gallego e Rios, 1991; Odorizzi, 1995; Maslach e Leiter,1997; Aluja,1997, Gatto, 2000 e BenevidesPereira, 2002 agrupam essas reações basicamente em quatro categorias: Físicas, Psíquicas, Comportamentais e Defensivas.

O Quadro 2, em um resumo esquemático, identifica as reações específicas que compõem cada uma dessas categorias.

Movimento, Porto Alegre, v. 10, n. 1, p. 183-209, janeiro/abril de 2004 
Quadro 2. Reações corporais associadas à SEP

Fonte: Quadro esquetnático adaptado de Benevides-Pereira, 2002, p.44.

\begin{tabular}{|c|c|}
\hline \multicolumn{2}{|c|}{ REAÇŌES } \\
\hline FISICAS & COMPORTAMENTAIS \\
\hline $\begin{array}{l}\text { Fadiga constante e } \\
\text { progressiva;Distúrbios do } \\
\text { sono;Dores musculares ou } \\
\text { osteomusculares;Cefaléias e } \\
\text { enxaquecas;Perturbaçôes } \\
\text { gastrintestinais;imunodeficiência; } \\
\text { Transtornos cardiovasculares; } \\
\text { Distúrbios do sistema respiratório; } \\
\text { Disfunçǒes sexuais; }\end{array}$ & $\begin{array}{l}\text { Negligencia ou excesso de } \\
\text { escrúpulos;Irritabilidade;Incremento } \\
\text { da agressividade;Incapacidade de } \\
\text { relaxar;Dificuldade na aceitaçảo de } \\
\text { mudanças;Perda da iniciativa; } \\
\text { Aumento do consumo de } \\
\text { substancias;Comportamento de alto } \\
\text { risco;Suicídio. }\end{array}$ \\
\hline PSÍQUICAS & DEFENSIVAS \\
\hline $\begin{array}{l}\text { Falta de atenção, de } \\
\text { concentração;Alteraçōes de } \\
\text { memória;Lentificaçăo do } \\
\text { pensamento;Sehtimento de } \\
\text { alienação;Sentimento de solidāo; } \\
\text { Impaciência;Sentimento de } \\
\text { insuficiência;Baixa auto-estima, } \\
\text { Dificuldade de autoaceitação; } \\
\text { Astenia, desânimo, depressāo; } \\
\text { Desconfiança, paranóia. }\end{array}$ & $\begin{array}{l}\text { Tendência ao isolamento;Sentimento } \\
\text { de onipotência;Perda do interesse } \\
\text { pelo trabalho (ou até pelo lazer); } \\
\text { Absenteísmo;Ironia, Cinismo. }\end{array}$ \\
\hline
\end{tabular}

A autora acrescenta que, uma pessoa com a Síndrome do Esgotamento Profissional não necessariamente deva a vir a denotar todos essas reações. O grau, o tipo e o número de manifestações apresentadas dependerão da configuração de fatores individuais, fatores ambientais e a etapas em que a pessoa se encontre no processo de desenvolvimento da síndrome. Lembra, também, que várias dessas reações são características dos estados de estresse; no entanto, os que se referem aos distúrbios defensivos são mais freqüentemente apresentados nos processos de esgotamento profissional.

\section{Fatores que tendem a agravar ou minimizar os efeitos da Síndrome do Esgotamento Profissional}

Alvarez et al (1993) e Odorizzi (1995) destacam dois grandes grupos de variáveis mais significativas que interferem até o momento da síndrome: as pessoais e as profissionais.

Movimento, Porto Alegre, v. 10, n. 1, p. 183-209, janeiro/abril de 2004 


\section{Pessoais}

Entre as variáveis pessoais destacam-se com ênfase no caráter mais sociológico:

A idade do sujeito em relação à quantidade de experiência em sua profissão. Parece ser que, quando os anos avançam se vai adquirindo maior segurança nas tarefas e menor vulnerabilidade a tensão laborai. Para Benevides-Pereira (2002), alguns autores atribuem a pouca experiência acarretando insegurança ou ao choque diante da realidade do trabalho, quando verificam que suas ilusões não possuem sustentação enquanto outros acreditam-se tratar de uma crise de identidade profissional diante das dificuldades de socialização encontradas. A síndrome começa a se manifestar desde o início do trabalho profissional, podendo, entretanto, vir a exteriorizar-se mais adiante. Para Codo e Vasquez-Menezes (1999), a síndrome atinge os valores mais elevados entre 10 e 15 anos de experiência na função docente, decrescendo posteriormente.

Gênero e variáveis familiares. Segundo estudos de Maslach e Jackson (1986), parece que as mulheres suportam melhor do que os homens as situações conflitivas no trabalho, ou seja, os professores homens culpam a síndrome a conduta dos alunos e ao marco estritamente laborai enquanto as mulheres o relacionam mais a sua própria falta de competência, de tempo livre, de reconhecimento social e de camaradagem entre os colegas. Em relação às variáveis familiares parece que a estabilidade afetiva de ser pai e mãe melhora o equilíbrio que se requer para resolver situações conflitivas. Segundo alguns estudos, não é somente a situação familiar a variável associada à síndrome senão, principalmente, o lugar que a família ocupa frente ao trabalho entre os profissionais que dão prioridade ao ensino sobre sua vida familiar.

Personalidade. Estudos realizados por McCaulley citado por Alvarez et al. (1993) aponta que os servicos educativos, em especial a docência, dominam o "tipo emocional", frente a uma personalidade de "tipo racional", com uma proporção de $80 \% / 20 \%$. As pessoas do primeiro tipo teriam a sensibilidade desenvolvida frente a matérias relacionadas com o trato humano, e uma necessidade de atividades corporativas, de afeto e entusiasmo. Dentro do segundo tipo, estariam os sujeitos que desenvolvem 
um grande poder de análise, objetividade e visão lógica dos sucessos junto com um grande ceticismo.

Sentido de coerência. Para Benevides-Pereira (2002), esse sentido tem a ver com o posicionamento diante da vida, é uma maneira de enfrentar as vicissitudes, utilizando principalmente os componentes cognitivos. A ênfase está nos aspectos positivos e não nos negativos implicados.

Motivação. Para Carlotto (2001), pessoas com motivação muito elevada em relação a sua profissão tendem a estar mais propensas à síndrome. Talvez, para esses, a frustração seja maior se não alcançarem êxito pessoal no trabalho.

Idealismo. Referindo-se às possibilidades de realização profissional, quanto maior o idealismo mais possibilidade de apresentar a síndrome. Um alto índice de idealismo muitas vezes está associado a expectativas elevadas e, muitas vezes, pouco realistas. No entanto, quando associado ao otimismo pode levar a baixos índices da síndrome (Gil-Monte e Peiró, 1997).

\section{Profissionais}

As variáveis profissionais têm sido as mais estudadas nos últimos anos, por possuírem o potencial suficiente para crer, por si só, em uma sensação persistente de mal estar ou bem de satisfação, segundo se apresentam em um sentido ou outro. É o resultado do fracasso das escolas e sua organização para responder tanto às demandas públicas em geral quanto às necessidades dos professores dos círculos docentes. Conforme Odorizzi (1995), as variáveis se dividem em:

Intrinsecas

São inerentes ao próprio conteúdo do trabalho. Entre elas, citase:

Autonomia ou liberdade que dão ao profissional para que decida. À medida que os professores aumentam sua hierarquia, seu poder de decisão aumenta, decrescendo, assim, os níveis da síndrome.

Variações ocupacionais. O docente se vê submetido a muitas de suas horas de trabalho com atividades burocráticas para as quais não estão preparados, como também baixam seu grau de motivação.

Movimento, Porto Alegre, v. 10, n. 1, p. 183-209, janeiro/abril de 2004 
Volume de trabalho. O volume ou a sobrecarga de trabalho, conforme Benevides-Pereira (2002), tem sido uma das variáveis mais predisponentes a síndrome, ou seja, quando a quantidade e a qualidade das demandas de trabalho ultrapassam a capacidade de desempenho pessoal.

A importância do trabalho. A falta de reconhecimento social da profissão aparece associados à síndrome. Essa situação, conforme Esteve (1994), se dá conjuntamente com as informações que os professores dão de sua desvalorização social de seu trabalho.

Promoção e desenvolvimento pessoal. Carlotto (2001) salienta que as pessoas que possuem altas discrepâncias entre suas expectativas de desenvolvimento profissional e aspectos reais de seu trabalho apresentam maiores níveis da síndrome.

\section{Extrínsecas}

Agrupam-se em três dimensões: Físicas, Social e Organizacional

Física: Incluem todas as variáveis relativas às condições de habitabilidade em que se realiza o trabalho (ruído, luz, espaço decoração, etc.)

Dimensão social: A este respeito, Benevides-Pereira (2002) afirma que, apesar de qualquer pessoa poder vir a sofrer de estresse ocupacional em função das atividades desenvolvidas, a síndrome incide principalmente nos que prestam ajuda, entre eles, os professores. Estariam incluídas aí, todas as pessoas em que o profissional estaria em contato (colegas, chefe, diretores, supervisores, etc.)

Dimensão Organizacional: Fariam parte desta dimensão os elementos relativos ao tempo investido em excessivos trâmites burocráticos, a estrutura hierárquica da instituição e as linguagens implícitas e explícitas próprias de normas, regulamentos, etc.

No caso dos profissionais da Educação, as variáveis que mais parecem contribuir para o surgimento do cansaço profissional são as condições ambientais deficientes e a escassez de material, a responsabilidade por um número cada vez maior de funções para as quais não foram devidamente preparados, as cobranças do desempenho e uma postura coerente numa sociedade em transformação, os conflitos surgidos ao compactuar com

Movimento, Porto Alegre, v. 10, n. 1, p. 183-209, janeiro/abril de 2004 
diferentes papéis em ocasiões contraditórias (amigo do aluno, professor do filho ou de outro familiar, prestando-lhes uma atenção individualizada sem desatender o grupo), o status socioeconômico determinando a continuação e o respeito social e não ao esforço realizado na execução da tarefa, o pouco apoio da organização escolar e dos colegas, o interesse ou implicação com os alunos, o absenteísmo, os hábitos perniciosos, a ansiedade e o estresse generalizado.

No tocante às variáveis de treinamento profissional, Esteve (1994) evidencia que todos os autores concordam sobre o fato de que a falta de formação prática nas escolas e centro universitários vem a ser uma dívida para os jovens que iniciam no exercício do trabalho docente. Os erros mais comuns na visão do autor seriam:

excessivo conhecimento teórico;

escasso treinamento em habilidades práticas;

Inexistência de aprendizagem de técnicas de autocontrole e manejo da própria ansiedade;

falta de informação sobre o funcionamento das organizações que vão desenvolver seu trabalho;

enfrentamento de valores, metas pessoais, auto-exigências profissional e monótono exercício diário da docência.

\section{Os efeitos da Síndrome de Esgotamento Profissional nos professores}

A síndrome tem sido associada a vários tipos de disfunções pessoais e a resultados organizacionais negativos podendo levar a uma deteriorização do desempenho do indivíduo no trabalho, afetando, também, às relações familiares e sociais. Segundo Esteve (1994), os principais efeitos da SEP em professores são:

1. sentimentos de desconcerto e insatisfação frente aos problemas reais da prática de ensinar;

2. desenvolvimento de esquemas de inibição, como forma de cortar a implicação pessoal com o trabalho que realiza;

Movimento, Porto Alegre, v. 10, n. 1, p. 183-209, janeiro/abril de 2004 
1. pedidos de transferências como forma de fugir de situações conflitivas;

2. desejo de abandonar a docência (realizado ou não);

3. absenteísmo do trabalho como mecanismo para cortar a tensão acumulada;

4. esgotamento, cansaço físico permanente;

5. ansiedade de espera;

6. estresse;

7. depreciação de si mesmo, culpa-se ante a incapacidade para qualificar o ensino;

10. ansiedade como estado permanente, associada como causaefeito a diversos diagnósticos de enfermidade mental;

11. depressão.

Benevides-Pereira (2002) assinala que o professor sente-se exausto necessitando buscar mais energia para tentar concentra-se no que está realizando desmotivado pela baixa satisfação. A falta de atenção e concentração predispõe a acidentes. Há Uma intenção ao abandono da profissão, tendo sido apontadas grandes perdas tanto pessoais pelo desperdício de tempo e saúde investidos, assim como para a instituição que terá que arcar Com seleção e treinamento de novo funcionário, perdendo não só tempo, como também produtividade.

Do ponto de vista social, há uma tendência ao isolamento. Nem sempre a família suporta o incremento dos sintomas já descritos levando, em muitos casos, ao divórcio.

Dentro das conseqüências organizacionais, o autor cita o absenteísmo, ou seja, o número de faltas ao trabalho, aumenta à medida que o processo de avanço da síndrome também au-menta. As faltas passam a ser uma forma de "respiro" para tentar levar adiante uma situação cada vez mais insustentável. Muitas vezes, como uma forma de não abandonar a carreira, nuima tentativa de solução do problema, a pessoa muda de instituição ou de setor dentro da organização (rotatividade), ocasionando a necessidade de um remanejamento de pessoal ou de nova contratação. Há, também, uma baixa produtividade no trabalho devido ao estado de esgotamento, desatenção, lentidão, irritabilidade e insatisfação.

Movimento, Porto Alegre, v. 10, n. 1, p. 183-209, janeiro/abril de 2004 


\section{Síndrome do Esgotamento Profissional: estratégias de intervenão e prevenção}

No entender de Freitas (2002), a SEP é, sem dúvida, uma patologia grave, quer pelo sofrimento que causa a quem dela padece, pela diminuição acentuada do rendimento no trabalho, quer pela perturbação que causa no relacionamento interpessoal, pelo absenteísmo e perturbação que provoca nas instituições.

Já, para Capilla Pueyo (2002), não existe nenhuma estratégia simples capaz de prevenir ou tratar a síndrome. Utilizam-se modelos complementares que tratam o indivíduo, o grupo social e a administração. Os programas de intervenção se desenvolvem em três níveis estratégicos: a) individual: considerando estratégias de enfrentamento ao estresse; b) interpessoal: potencializando a formação* de habilidades sociais e as estratégias relacionadas com o apoio social no trabalho; e c) organizacional.

Em nível individual, as estratégias são centralizadas na aquisição e melhoria de estilos de enfrentamento. Localizam-se as técnicas de resolução de problemas, manejo do tempo de forma eficaz, otimização da comunicação, mudanças do estilo de vida. O autor recomenda, ainda, aumentar a competência profissional, propiciando a investigação; redesenhar a execução fazendo as coisas de forma diferente; distrações extralaborais, praticando exercícios físicos, esportes, relaxamento, tendo um hobby particular; fazer pequenos momentos de descanso (pausas) durante o trabalho; estabelecer metas reais e factíveis de alcançar e, como último recurso para não abandonar a profissão, mudar de posto dentro e fora do sistema de ensino.

No âmbito pessoal, têm-se utilizado técnicas de enfrentamento do estresse e ensaio de condutas. $\mathrm{O}$ autor acredita ser fundamental a orientação aos novos profissionais que iniciam a carreira, pois podem apresentam uma negação parcial do risco que sofrem devido à inexperiência e ao otimismo de controlar a situação. Para enfrentar a síndrome é imprescindível fortalecer os vínculos sociais entre os trabalhadores.

Por último, no âmbito organizacional dever-se-ia estimular-se o suporte real ao profissional afetado, constituindo-se grupos de especialistas capazes de oferecer a ajuda necessária.

Movimento, Porto Alegre, v. 10, n. 1, p. 183-209, janeiro/abril de 2004 
Ao tratar este tema, França e Rodrigues(1997), numa abordagem terapêutica diz que o ideal é a prevenção. A síndrome é evitável e passível de cura, mas sua prevenção e tratamento são difíceis. E preciso mudar conceitos a respeito de valores, do que é desejável, do que é bom para o indivíduo; é necessário vencer pressões do meio social, profissional e familiar; há problemas econômicos e vivenciais. É preciso, muitas vezes, mudar toda uma filosofia de vida. Uma vez estudada a presença da SEP em professores, Esteve (1994) distingue duas diferentes possibilidades de solução:

1. em primeiro lugar, é preciso fazer uma prevenção, que, a partir das deficiências e lacunas constatadas no período de formação inicial dos professores, estabeleça mecanismos seletivos adequados para o acesso da profissão baseada não somente pela sua qualificação intelectual, mas, também, em critérios de personalidade, e se busque maior adequação dos conteúdos da formação inicial a realidade prática de ensino, permitindo ao futuro professor tanto a compreensão e o domínio técnico dos principais elementos que modificam a dinâmica de seus grupos de alunos, quanto a dos elementos sociais cuja ação contextual acaba influenciando a relação educativa;

2. em segundo lugar, no âmbito da administração educacional, convém articular estruturas de ajuda para os professores em exercício. Pode-se compreender, comparativamente, que o processo de formação permanente tem menor importância que a prevenção do processo de formação inicial para evitar o esgotamento profissional. Se o professor iniciante superar o choque com a realidade, apesar de que, com o método custoso e prejudicial de aprendizado por ensaio e erro, as tensões iniciais se reduzam, conforme se sente aceito pelos alunos, pais e colegas, inicia, então, a possibilidade de autorealização com o trabalho profissional com inovações que permitem uma expressão mais pessoal do papel que desempenha na instituição.

Assim, em decorrência deste enfoque, Medina (2002) pontua que a prevenção da síndrome é complexa já que implicaria uma reestruturação de Sistemas de Ensino público e privado, porém, atualmente está se levando em conta, igualmente, outros problemas dentro da normativa de Saúde Laborai e Higiene no Trabalho esperando que diminua sua incidência no curto e médio prazos.

Movimento, Porto Alegre, v. 10, n. 1, p. 183-209, janeiro/abril de 2004 


\section{Considerações finais}

Considerando-se a SEP um problema psicossocial e com implicações pedagógicas que afeta múltiplas profissões, o interesse e a preocupação pelo tema estão atraindo estudiosos de entidades governamentais nacionais e internacionais. No Brasil, embora com um avanço significativo nas pesquisas, necessita-se, por parte de estudiosos da área, e dos novos pesquisadores, de um maior aprofundamento sobre o tema. Crê-se que, à medida que se entender melhor como a síndrome inicia e como evolui com o passar do tempo, sua reação no organismo e suas conseqüências, criando mecanismos que permitam o seu diagnóstico precoce ter-se-á maiores condições para interferir em ações de prevenção.

Concorda-se com Carlotto e Gobbi (2000) quando destacam a importância da mudança na revisão de valores que regem a instituição, resgatando os valores humanos no trabalho, e que, para garantir a saúde física, mental e a segurança social do sujeito, isso não depende de uma só parte, mas, sim, simultaneamente do próprio trabalhador e da organização. Faz-se necessário traçar programas de melhoria do ambiente e no clima organizacional, através de políticas de trabalho eficazes, com o intuito de aumentar a motivação, evitando sentimentos de desilusão, solidão e frustração que tomam conta de muitos profissionais do ensino, aumentando, assim, a qualidade de vida do professor e, conseqüentemente, dando respostas positivas à organização e à sociedade.

Devido à carência de pesquisas abrangendo áreas específicas da Educação não se pode afirmar que a SEP ocorra mais em docentes das áreas de Química, Matemática, Física, Biologia e outras, do que no âmbito da Educação Física, e, tampouco se pode precisar que o problema seja mais visível nas mulheres do que nos homens. Embora se possa estabelecer algumas relações em nível das fontes que lhe dão origem, crê-se que na Educação Física, esse assunto necessita de aprofundamento, pois, o professor, mesmo trabalhando, muitas vezes em condições desfavoráveis, é considerado um agente transformador pela comunidade.

Movimento, Porto Alegre, v. 10, n. 1, p. 183-209, janeiro/abril de 2004 
Diferentemente de outras áreas, na presente investigação encontram-se poucos estudos sobre essa temática específica, a Educação Física. Devido a sua própria característica, que tem no contato direto e envolvimento afetivo professor/aluno a capacidade de detectar, através de suas aulas, problemas específicos dos alunos procurando modificar atitudes apontando soluções, crê-se que, somente através do aumento nas pesquisas envolvendo especificamente a área da Educação Física, poder-se-á obter dados significativos para identificar se o professor está ou não mais suscetível a experimentar a SEP do que docentes de outras áreas do ensino.

Por fim, pode-se sugerir pesquisas específicas relacionadas à área da Educação Física, por exemplo, envolvendo os seguintes questionamentos:

1. Como se caracteriza o processo de desistência da prática docente e da prática pedagógica em relação à Síndrome do Esgotamento Profissional nos professores de Educação Física?

2. Qual a relação existente entre a Síndrome do Esgotamento Profissional, trabalho docente e prática pedagógica no processo de abandono de professores das diferentes áreas de ensino?

Acredita-se que estudos com essa problemática poderão ter efeitos interessantes não somente para a formação dos professores de Educação Física, mas, também, em seu trabalho cotidiano nas escolas.

Movimento, Porto Alegre, v. 10, n. 1, p. 183-209, janeiro/abril de 2004 
Síndrome del Agotamiento Profisional: revisión de bobliografía

Resumen: En las últimas décadas, pesquisadores de varias áreas se han preocupado con lo fenómeno Síndrome del Agotamiento Profesional (SEP), caracterizado como enfermedad del trabajo. Considerada el nivel más avanzado del stress, la SEP afecta innumerables profesiones, principalmente aquéllas en que los profesionales poseen contacto directo con personas, entre los cuales, los profesores. La revisión bibliográfica con textos en lengua portuguesa, inglesa y española sobre el tema permitió unificar la expresión del fenómeno como "Síndrome del Agotamiento Profesional" (SEP). El aprofundamiento de estudios sobre este fenómeno en determinados colectivos docentes, como los profesores de Educación Física, posibilitará ampliar la compreensión y elaborar significativos cuestionamientos abarcando el trabajo docente y el fenómeno descrito en la bibliografía.

Se destaca que en esa revisión de literatura, fueron encontrados pocos trabajos que se refieran a colectivos de trabajadores docentes. En el caso de los profesores de Educación Física, foco de interés e investigativo de este estudio, pocos los trabajos encontrados sobre el asunto. Palabras-clave: "Burnout", Síndrome del Agotamiento Profesional, Profesores de Educación Física.

Burnout Syndrome - literature review Abstract: In the past decades, researchers in different fields have studied burnout, the phenomenon (BS) characterized as an occupational disease. Considered the advanced stage of stress, the BS affects a number of professionals, especially those who work directly with people, such as teachers. The review of the literature available on the subject in Portuguese, English, and Spanish allowed the author to unify the expression of the phenomenon as "Burnout Syndrome" (BS). A careful study of this phenomenon in given teaching groups, such as Physical Education teachers, will broaden the understanding of it and will allow for the raising of meaningful questions involving teaching, and the phenomenon described in the literature.

Movimento, Porto Alegre, v. 10, n. 1, p. 183-209, janeiro/abril de 2004 
To be pointed out is that, in the literature review, the author were found across few studies of groups of teachers. More specifically, in the case of Physical Education teachers, which is the author's focus of research, few references on the subject. Keywords: "Burnout", Burnout Syndrome, Physical Education teachers.

\section{Referencias}

ALUJA, A. Burnout profesional em maestros y su relación con indicadores de salud mental. Boletín de Psicología, n. 55, p. 47 - 61, jun. 1997.

ALVAREZ, C. D et al. Revisión teórica del burnout o desgaste profesional en trabajadores de la docência. Canoas, Ceasura, n. 2 Jan/jul, p. 47 - 65, 1993.

BALLONE, G. J. Síndrome de Burnout In: PsiqWeb Psiquiatria Gera Internet, última revisão, 2002. Disponível em: http://www.psiqweb.med.br/cursos/ stress4.html. Acesso em 18 set. 2002.

BENEVIDES-PEREIRA A. M. T. (org.) Burnout: Quando o trabalho ameaça o bem-estar do trabalhador. São Paulo. SP: Casa do Psicólogo, 2002.

BRASIL. Ministério da Previdência Social. Decreto 3048/99. Anexo II 1999

BUSSING, A. \& GLASER, J. Four-stage process model of the core factors of Burnout: the role of work-related resources. Work \& Stress, 14, 329-346, 2000.

CAPILLA - PUEYO, R. El síndrome de Burnout o de desgaste profesional, mar. 2000 , v. 58 , n. 1334. Disponível em: http//www.demasiado.com/cengarle/ burnout.htm. Acesso em 19 set. 2002.

CARLOTTO, M. S. Síndrome de "Burnout": um tipo de estresse ocupacional. Caderno Universitário; n. 18.:Universidade Luterana do Brasil, Canoas 2001, 52 p.

CARLOTTO, M. S.; GOBBI, M. D. Síndrome de Burnout: um problema do indivíduo ou do seu contexto de trabalho? Alethéia, n.10, p. 103 -114, jul/dez, 2000.

CARRARO, A., TISATO, F, COGNOLATO, S. \& BETOLLO, M. Burn out risk for physichal education teachers. Actas del II Congreso Mundial de la Actvidad Física y el Deporte: Deporte y Cualidad de Vida. p.54-59.Granada/ES: Universidad de Granada, 2003.

CID-10 Classificação estatística internacional de Doenças e problemas relacionada à saúde. Décima revisão. V. 1. Ed. USP, São Paulo, 1988.

CODO, W.; VASQUES-MENEZES, I. O que é burnout? In: CODO, W. (Org.), Educação: Carinho e Trabalho. Petrópolis: Vozes, 1999.

CORSI, J. El síndrome "Burnout". Síndrome de estrés crônico en profisionales que trabajan em el campo de la violência familiar. Disponível em: http:// www.fempress.cl/219/revista/219_burnout.html. Acesso em 20 abr. 2002.

Movimento, Porto Alegre, v. 10, n. 1, p. 183-209, janeiro/abril de 2004 
CORREIO BRAZILIENSE. No limite da tensão e do esgotamento. Zero Hora, Porto Alegre, 5 mai. 2002.

EROSA, M. El stress. Disponível em http:www.lucas.simprenet.com/trabajos/ stress/.htm. Acesso em 24 jul. 2000.

ESTEVE, J. M. El malestar docente. 3 ed. revisada y ampliada. Ediciones Paidós Ibérica, S. A. Barcelona, 1994.

FARBER, B. A. Stress and burnout in suburban teachers. Journal of Educational Research., Washington, v. 77, n. 6, p. 325 - 331, 1984.

FIRTH, J. Personal meanings of occupational stress: cases from clinic. Jounal of Occupational Psicology, 58, 139 - 148, 1985.

FRANÇA, H. H. A Síndrome de Burnout. Revista Brasileira de Medicina, v. 44, n. 8, p. 197 - 199, 1987.

FRANÇA, A. C. L; RODRIGUES, A. L. Stress e Trabalho: Guia básico com abordagem psicossomática. São Paulo: Atlas, 1997.

FREITAS, F. de. O esgotamento (Burnout) nos professores. Disponível em: http://www.ipv.pt.millenium/15_epec1.htm. Acessado em 17 set. 2002.

FREUDENBERGER, H. J. Journal of Social Issues, New York, n. 30, p. 159 - 165, 1974.

GALLEGO, A.; RIOS, L. F El síndrome del "Burnout" o el desgaste profesional (I): revisión de estudios. Revista da Asociación Española de Neuropsiquiatria, Madrid, v. 11, n. 39, p. $257-265,1991$.

GATTO, M. E. Desgaste psíquico em el equipo de salud - Síndrome de Burnout. Disponível em: http;//hva.com.ar/psicooncologia/Síndrome de Burnout.htm. Acesso em 18jul. 2000.

GIL-MONTE, R R. El sindrome de quemarse por el trabajo (Sindrome de Burnout): Aproximaciones teóricas para su explicación y recomendaciones para la intervención. Disponível em: http://www.psycologia.com/articualos/ar-pgil.htm. Acesso em 19 set. 2002.

GIL-MONTE, R R. Perspectivas teóricas y modelos interpretativos para el estúdio del sindrome de quemarse por el trabajo. Na. De Psicol., Murcia, v. 15, n. 2, p. $261-268$, 1999.

GIL-MONTE, RR.; PEIRÓ, J. M. Desgaste psíquico en el trabajo: el síndrome de quemarse. Madrid, Sínteses, 1997.

GONZÁLEZ, M. J. Una evaluación del estrés laboral. Ansiedad y Estrés, 1, 205 - 218. 1995.

GONZÁLES HERRERO, E., MONFORT PAÑEGO, M., PASCUAL BAÑOS, C. La materia de educación física como desencadeante del burn out en el profesorado. Actas del II Congreso Mundial de la Actividad Física y el Deporte: Deporte y Cualidad de Vida. pp. 127-131. Granada/ES. Universidad de Granada, 2003.

HERRERO, L H.; GONZÁLEZ, J. L R. \& MARTíN, M. J. R. R. Estrés laboral y variables biomédicas. $2^{\circ}$ Congreso Virtual d Psiquiatría. In: www. psiquiatria.com/ congreso, 2001.

Movimento, Porto Alegre, v. 10, n. 1, p. 183-209, janeiro/abril de 2004 
JIMÉNEZ, M. B., GUTIÉRREZ, J. L G., HERNÁNDEZ, E. G. Burnout docente, sentido de la coherencia y salud. Revista de Psicopatología Clínica, (4), 3, p. 163 - 180. Faculdad de Psicología. Universidad Autônoma de Madrid, s/d.

MASLACH, C. "Burned-out" Human Behavior, v.5, n. 9, p. 22 - 26, 1976.

MASLACH, C. \& JACKSON, S. E. The messurement of experienced Burnout. Journal of Occupational Behavior, n .2, p. $99-113,1981$

MASLACH, C. \& JACKSON, S. Maslach Burnout Inventory. Palo Alto: Consulting Psysicologists Press, 1986.

MASLACH, C. \& LEITER, M. R The truth about burnout: how organization cause, personal stress and what to do about it. San Francisco: Jossey-Bass, 1997.

MASLACH, C; SCHAUFELI, W. B. \& LEITER, M. R Job Burnout. Annual Review of Psicology, 52, 397 - 422, 2001.

MAY, H. J. \&. REVICH, D. A. Professional stress among family physicians. Journal of Family Practice, 20, 165 - 171, 1985.

MEDINA, M. I. G. El sindrome de "Burnout" Disponível em: http:/l es.geocities.com/cenpsisa/burnout.html. Acessado em 19 de set de 2002.

MORAES, C. V. Tratando de quem trata: atendimento aos serviços de saúde. Anais do Congresso Interamericano de Psicologia da Saúde. São Paulo, Faculdade de Medicina da Universidade de São Paulo. M7, 2001.

MOURA, E. R G. Saúde mental e trabalho: Esgotamento profissional em professores da rede de ensino particular de Pelotas - RS. Dissertação de mestrado em Psicologia Social e da Personalidade - Faculdade de Psicologia, Pontifícia Universidade Católica do Rio Grande do Sul, Porto Alegre, 1997.

NUNES, R. As alterações psicológicas induzidas pe/o stress profissional nos enfermeiros. Monografia de Licenciatura em Psicologia Clínica. Lisboa, Instituto Superior de Psicologia Aplicada, 1989

ODORIZZI, C. M. A. Síndrome de Burnout: uma resposta a um estresse crônico. Revista do Professor, Porto Alegre, 11 (43): 44 - 45, jul./set. 1995.

OLIVEIRA, J. R. A Síndrome de Burnout nos cirurgiões-dentistas de Porto Alegre, RS. Dissertação de Mestrado em Odontologia - Faculdade de Odontologia, Pontifícia Universidade Católica do Rio Grande do Sul, Porto Alegre, 2001.

OLIVER, C. et al. La escala MBI como medida del estrés laboral assistência/. Rev. Cub. Psicol., Habana, v. 12, n. 3, p. 201 - 208, 1996.

OLIVER, C; PASTOR, J. C; ARAGONEZ, A. \& MORENO-JIMENEZ, B. Una teoría y una medida del estrés laboral e asistencial. II Congreso del Colegio Oficial de Psicólogos. Valencia, 291 - 297. 1990

REMOR, E. A. Professor: uma profissão estressante. Revista Opinião 2 - Disponivel em: http://www.sinpro-rs.org.br/extra/mar98/opiniao2.htm. Acesso em 18 set. 2002.

SCHAUFELI, W. Evaluación de riesgos psicosociales y prevención del estrés laboral: algunas experiencias holandesas. Revista del Psicología del Trabajo y de las Organizaciones, 15, 147-171, 1999

Movimento, Porto Alegre, v. 10, n. 1, p. 183-209, janeiro/abril de 2004 
SEISDEDOS, N. MBI Inventário "Burnout" de Maslach. Manual da tradução Espanhola. Madrid: TEA, 1997

SELIGMANN-SILVA, E. Psicopatologia e psicodinâmica no trabalho. In: Mendes, R. (org.) Patologia do Trabalho. Rio de Janeiro: Atheneu, 1995. Cap.12. p. 287-310.

SHORÒDER, M.; MARTÍN, E.; FONTANAIS, M. D. \& MATEO, D. Estrés ocupacional em cuidados paliativos de equipes catalãs. Medicina Paliativa, 3, 170 - 175, 1996.

SILVA, F. R R Burnout: Um desafio à saúde do trabalhador. Artigos burnout, v. 2, n 1 jun./2000. Disponível em: http://www2.uel.br/ccb/psicologia/revista/ textov2n15.htm. Acessado em 17 set. 2002

STELLA, M. I. J. As exigências do novo milênio, como fator desencadeante das neuroses profissionais. Anais do Congresso Interamericano de Psicologia da Saúde. São Paulo, Faculdade de Medicina de Universidade de São Paulo. TL54, 2001.

VILLALOBOS, J. O. Estrés y trabajo. Disponível em: http://www.medspain.com/ n3 feb99/strees.htm. Acesso em 7 out. 2002. 